\title{
Correction to: Primaquine Loaded Solid Lipid Nanoparticles (SLN), Nanostructured Lipid Carriers (NLC), and Nanoemulsion (NE): Effect of Lipid Matrix and Surfactant on Drug Entrapment, in vitro Release, and ex vivo Hemolysis
}

Kai-Wei Wu ${ }^{1} \cdot$ Corinne Sweeney $^{1} \cdot$ Narendar Dudhipala $^{1} \cdot$ Prit Lakhani $^{1} \cdot$ Narayan D. Chaurasiya $^{2}$.

Babu L. Tekwani ${ }^{2}$ Soumyajit Majumdar ${ }^{1,3,4}$

Published online 20 December 2021

Correction to: AAPS PharmSciTech volume 22, Article number: 240 (2021)

https://doi.org/10.1208/s12249-021-02108-5

The original article has been updated to add additional corrections.

The original article has been corrected.

Publisher's Note Springer Nature remains neutral with regard to jurisdictional claims in published maps and institutional affiliations.

The original article can be found online at https://doi.org/10. 1208/s12249-021-02108-5.

${ }^{1}$ Department of Pharmaceutics and Drug Delivery, The University of Mississippi, 111 Faser Hall, University, MA 38677, USA

${ }^{2}$ Department of Infectious Diseases, Division of Drug Discovery, Southern Research, 2000 Ninth Avenue South, Birmingham, AL 35205, USA

${ }^{3}$ Research Institute of Pharmaceutical Sciences, University of Mississippi, University, MA 38677, USA

${ }^{4}$ To whom correspondence should be addressed. (e-mail: majumso@olemiss.edu) 